\title{
MOVIMENTOS DO PENSAMENTO: CENÁRIOS DA FILOSOFIA DO CORPO NO BRASIL
}

Terezinha Petrucia da NÓBREGA ${ }^{1}$; Liege Monique Filgueiras da SILVA ${ }^{2}$; Avelino Aldo de LIMA NETO ${ }^{3}$

${ }^{1}$ Programa de Pós-Graduação em Educação/UFRN e Programa de Pós-Graduação em Educação Física/UFRN. Email:pnobrega68@gmail.com

${ }^{2}$ Doutora em Educação/UFRN. E-mail: silvaliege@yahoo.com.br

${ }^{3}$ Instituto Federal de Educação, Ciência e Tecnologia do Rio Grande do Norte. Doutorando em Educação/UFRN e Université Paul Valéry. E-mail: avelino.lima@ifrn.edu.br

Artigo submetido em abril/2015 e aceito em junho/2015

DOI: $10.15628 /$ dialektike.2015.3047

\section{RESUMO}

O presente artigo tem por objetivo apresentar um panorama geral dos estudos de Filosofia do Corpo no Brasil. Partimos de uma contextualização filosófica acerca desse domínio de estudos para, em seguida, descrever a paisagem histórica de seu percurso no país. Posteriormente, apresentamos um recorte das pesquisas desenvolvidas no país de 2011 a 2012, concentrando-nos nos âmbitos dos programas de pós-graduação em Filosofia e em Educação. Por fim, analisamos as implicações epistemológicas dos atuais estudos e traçamos possibilidades de sua continuidade no cenário brasileiro de investigação.

PALAVRAS-CHAVE: Filosofia do Corpo; Corpo; Educação; Filosofia no Brasil.

\section{MOUVEMENTS DE LA PENSÉE: SCENÁRIOS DE LA PHILOSOPHIE DU CORPS AU BRÉSIL}

\section{RÉSUMÉ}

Cet article vise à présenter une vue d'ensemble des études de Philosophie du Corps au Brésil. D’abord, nous avons présenté le contexte philosophique sous-jacent à ce domaine d'étude. Ensuite, nous avons décrit le paysage historique de son parcours dans le pays. Par la suite, nous présentons un aperçu de la recherche menée dans le pays de 2011 à 2012, en se concentrant dans les domaines de programmes d'études de master et doctorat en Philosophie et en Éducation. Enfin, nous analysons les implications épistémologiques des études actuelles et ébauchons des possibilités de sa continuité dans le scénario brésilien de recherche. 
"Gosto de sentir a minha língua roçar A língua de Luís de Camões Gosto de ser e de estar

E quero me dedicar A criar confusões de prosódia E uma profusão de paródias (...)"

Caetano Veloso

Contra a audácia de quem pensa que só se pode filosofar em alemão - mas não só filosofar, como também escrever poesia e prosa - Caetano Veloso, em Língua, canção do álbum Homem comum (2003) faz a nossa língua perturbar as lógicas de submissão intelectual e artística. Não, não se filosofa só em Alemão, em Inglês, em Francês ou no Português de Luís de Camões, mas também, como dizem os colegas franceses - com os quais muitos linguistas, por sinal, concordam - também é possível filosofar em Brasileiro.

Não precisamos lembrar que a Língua não é somente a gramática instituída, mas a identidade de um povo trespassada por inúmeros elementos históricos, sociais e culturais. Na nossa Língua aglutinam-se elementos da experiência vivida, possível graças à existência incorporada. Uma Filosofia do Corpo alicerça-se no fato de que o nosso horizonte de pensamento se desenha e se efetua pelo fato de sermos corpo. Logo, seu pressuposto indispensável reside no corpo enquanto princípio epistemológico. Ademais, sendo sempre atravessado por uma construção identitária da qual a Língua é um componente -, a produção do saber passará sob a ótica desta identidade. A língua possui também um componente afetivo e expressivo que faz com as palavras ganhem um sentido para nós, como nos indica Merleau-Ponty ao considerar o corpo como expressão e linguagem, e sobretudo ao considerar a linguagem como prosa do mundo (MERLEAU-PONTY, 1945; 1969).

Ao explorar os cenários da Filosofia no Corpo no Brasil, realizamos três movimentos: inicialmente, apresentamos, em linhas gerais, a contextualização filosófica e histórica dessa área de estudos. Em seguida expomos um recorte das pesquisas recentes desenvolvidas no país de 2011 a 2012, concentrando-nos nos âmbitos dos programas de pós-graduação em Filosofia e em Educação. Por fim, analisamos as implicações epistemológicas dos atuais estudos e traçamos possibilidades de sua continuidade no cenário brasileiro de investigação.

\section{AS FILOSOFIAS DO CORPO, OS CORPOS DA FILOSOFIA}

Não é necessário lembrar a presença constante do corpo História da Filosofia. Isso nos mostram, em exaustão, os manuais. Aqui contentamo-nos em circunscrever a localização do corpo enquanto interesse de pesquisa num cenário epistêmico específico, desenvolvido mormente a partir do século XX. Tal cenário dá origem ao que denominamos hoje de Filosofia do Corpo.

Andrieu (1993) ressalta que a dispersão epistêmica à qual o corpo foi submetido por meio da Psicanálise, da Fenomenologia e das Neurociências ao longo do último século foi decisiva para engendrar o campo de pensamento em questão. A produção de modelos distintos para a análise da experiência vivida, do inconsciente e do cérebro gerou tensões no interior das ciências humanas, dadas algumas pretensões de explicações totalizantes e, por conseguinte, excludentes. 
Ao mesmo tempo e paradoxalmente, tal tensão foi a origem da fecundidade para esta área de estudos, haja vista que, a partir dela, produziram-se discursos múltiplos sobre o corpo e sobre o fenômeno da incorporação. Encontramo-nos, assim, diante de um objeto eminentemente interdisciplinar, dinâmico e com um campo epistemológico multirreferencial, que impõe desafios de ordem teórica e metodológica (ANDRIEU, 2006; NÓBREGA, 2010).

No que concerne especificamente à Filosofia, foi por meio da fenomenologia de Husserl e, posteriormente, pela de Merleau-Ponty, que a Universidade reconheceu o problema do corpo (ANDRIEU, 2002). A partir de então, os domínios de interesse deste campo passam a se desenhar de modo mais nítido. Pode-se dizer que Filosofia do Corpo interessa-se pela amplidão de experiências possíveis no, com e através do corpo, bem como nas implicações éticas, políticas e sociais daí oriundas. Na verdade, a própria noção de experiência - que, como sabemos, desde as origens da teoria do conhecimento no Ocidente sempre esteve intrinsecamente associada ao problema do corpo - recebe uma profusão de novos ângulos de análise.

Sabemos que o corpo não é um objeto novo para a Filosofia. No entanto, uma Filosofia do Corpo, nascida de um novo contexto - o da dispersão epistêmica acima sublinhada - trouxe paisagens filosóficas originais no século $X X$ e nestes primeiros anos do século $X X I$. $O$ desenvolvimento dos pressupostos da fenomenologia, das ciências cognitivas, das neurociências, da etologia, da psicologia do desenvolvimento, reforçou a necessidade de problematizar ainda mais o postulado da unidade somatopsíquica (ANDRIEU, 2010, p. 12-13), mas também o de reconfigurar a experiência corporal na história, nas artes, na vida social. A dispersão fez nascer, assim, uma proliferação de novos discursos em torno dessa experiência, gerando novos influxos, tanto na ordem teórica quanto metodológica.

Nesse sentido, seria mais apropriado falarmos em Filosofias do Corpo, haja vista ser preciso considerar as múltiplas tentativas filosóficas desenvolvidas para pensar as diversas nuances do fenômeno da incorporação. Isso faz com que a Filosofia do Corpo seja, ao mesmo tempo, filosofia dos muitos corpos possíveis: o corpo sexuado, (des)generificado ou de desejos; o corpo da atleta, do dançarino, do ator; o corpo do professor e do estudante; o corpo na mídia; o corpo do doente, do louco; o corpo nas artes visuais.

Poderíamos continuar a lista ad aeternum, pois quantos são os usos e as experiências do corpo, tantas podem ser as Filosofias do Corpo, que, ademais, lançam mão de abordagens teóricas e metodológicas variadas, a depender qual é o corpo a ser pensado. É essa miríade de abordagens que podemos vislumbrar nos cenários da Filosofia do Corpo no Brasil, sempre em interfaces com outros domínios do conhecimento. Em face dessa amplidão, optamos por circunscrever o nosso olhar às grandes áreas da Educação e da Filosofia, muitas vezes interligadas pelas pesquisas em Educação Física, como agora passamos a descrever.

\section{PAISAGENS DA FILOSOFIA DO CORPO NO BRASIL}

Um dos mais importantes campos de desenvolvimento de uma Filosofia no Corpo no Brasil foi a Educação Física. Em 1970, Mauro Soares Teixeira publica Fundamentos Filosóficos da Educação Física, obra que passa a ser referência para a pesquisa em Educação Física. Inezil Penna Marinho escreve sobre as relações do corpo e da alma em Aristóteles, Descartes e Bergson escritos que introduzirão uma Filosofia da Educação Física e dos Esportes, em 1944 Porém, já em 1944 ele havia publicado um importante artigo, que prefigurava o seu livro 0 hedonismo, uma 
filosofia do prazer, de 1971. Trata-se do texto O conceito bio-sócio-filosófico da Educação Física em oposição ao conceito anátomo-fisiológico (ANDRIEU; NÓBREGA, 2015).

Os anos oitenta no Brasil marcam a saída de uma ditadura de vinte e um anos. Fervilhavam mudanças nos âmbitos social, comportamental, cultural e também epistemológico. Nesse momento, os trabalhos de Manuel Sérgio, em Portugal, e Jean Le Boulch, na França, encontrarão, aqui, solo fértil. As noções de corpo próprio e motricidade farão surgir novos modos de pensar a Educação Física. No Brasil, os textos $A$ Educação Física cuida do corpo e mente: bases para a renovação e transformação da Educação Física (Medina, 1987) e Educação Física, uma abordagem filosófica da corporeidade (SANTIN, 1987) exercerão essa função. Estes autores apresentam uma crítica fenomenológica ao dualismo corpo e mente. Nessa direção, o livro Educação Física uma abordagem fenomenológica (MOREIRA, 1992) e Educação Física, ensino e mudança (KUNZ, 1991) desenvolveram os aspectos filosóficos da corporeidade no contexto escolar.

Nos domínios de práticas corporais como a dança, os temas da expressão e da consciência corporal também passam a fazer parte do discurso e da formação em Educação Física, seja na escola, seja na universidade. Nesse contexto, o livro Método Dança Física (CLARO, 1987) difundirá todo um conhecimento de técnicas corporais, tais como o método Feldenkrais e a Eutonia. A colaboração entre Edson Claro, professor da UFRN, e dançarinos, coreógrafos e somaticiens vindos da Argentina, como Patricia Stokoe (STOKOE, HARF, 1987), abriu caminhos singularmente expressivos para o corpo e para um novo pensamento estético no domínio da Educação Física em ambos os países.

Outras abordagens, notadamente históricas e sociais, baseadas sobre a cultura do corpo, contribuíram enormemente para as transformações significativas no pensamento sobre a corporeidade, a cultura do corpo e a cultura do movimento nos anos seguintes, a saber: Esporte para todos um discurso ideológico (CAVALCANTI, 1984) ; Educação Física e aprendizagem social (BRACHT, 1992) ; Metodologia do Ensino da Educação Física (COLETIVO DE AUTORES, (1992) ; Educação Física, raízes europeias e Brasil (SOARES, 1994) ; Da cultura do corpo (DAÓLIO, 1995).

Valter Bracht e seu grupo de pesquisa na UFES desenvolveu múltiplas contribuições em direção a um pensamento epistemológico do corpo e da Educação Física, notadamente em colaboração com outros autores de instituições da América do Sul. Isto é visível na obra Educação Física no Brasil e na Argentina : identidade, desafios e perspectivas (BRACHT; CRISÓRIO, 2003) e na coletânea Cuerpo y Educación Física; perspectivas latinoamericanas para pensar la educación de los cuerpos (VAREA; GALAK, 2013).

A Filosofia do Corpo agrega-se àquela do esporte através dos trabalhos sobre o conhecimento corporal, desenvolvidos por Daniel Calmels (1997; 2001) especialista em psicomotricidade e professor de Educação Física (BARREIRA \& MASSIMI, 2008). Cesar R. Torres (2006; 2008) desenvolve uma filosofia do esporte a partir de uma história dos corpos em movimento. A partir de filósofos da Escola de Frankfurt e alinhado ao pensamento de Michel Foucault, o conceito de corpo incerto foi descrito por Francisco Ortega (2008), da UFRJ. Já a história de práticas e imagens corporais foi estabelecida por Carmen Soares (1998), da UNICAMP.

Alexandre Fernandez Vaz e Viviane Teixeira Silveira (SILVEIRA ; VAZ, 2014), da UFSC, estudam a manipulação dos hormônios no doping e as suas consequências para a autonomia do sujeito. As pesquisas de Ana Marcia Silva, da UFG, centram-se nas relações entre o corpo e o discurso científico no domínio das ciências do esporte (SILVA, 2001). Também o faz Alex Branco Fraga, da UFRGS, notadamente no livro Exercício da informação: governo dos corpos no mercado da vida 
ativa (FRAGA, 2006). Amarílio Ferreira Neto, da UFES, trabalha sobre a epistemologia e o discurso científico da Educação Física (FERREIRA NETO, 2005).

Destacamos, por fim, algumas pesquisas que ultrapassam o domínio da Educação Física muito embora algumas delas nasceram neste campo e continuam, de algum modo, a ele vinculadas. Num percurso que faz a ligação entre o corpo, a estética e as artes, podemos citar o trabalho de Sandra Della Fonte, da UFES, marcado por pesquisas em torno da cultura, da arte e da psicanálise (DUARTE; DELLA FONTE, 2010). Homero Luís, na UFCE, concentra-se sobre o póshumanismo e a biotecnologia (LIMA, 2010). Iraquitan Caminha $(2010 ; 2012)$ trabalha a filosofia do corpo e da percepção em perspectiva fenomenológica, na UFPB. Petrucia da Nóbrega $(2000 ; 2008$; 2010), da UFRN, foca-se sobretudo na fenomenologia de Merleau-Ponty, desenvolvendo, a partir da prática da dança, uma ligação entre o corpo vivo e o corpo vivido. Destaca-se também uma Filosofia do Corpo a partir de Kant, englobando os temas do gênero e da sexualidade, tais como podemos ler nos trabalhos de Cinara Nahra (2011), da UFRN, de Maria Borges (2011), da UFSC, e de Lima Neto (2013), do IFRN.

Os intercâmbios franco-brasileiros do Grupo de Pesquisa Estesia, da UFRN, com os professores Claude Imbert (École Normale Supèrieur /Paris), Jacques Gleyse (Universidade de Montpellier) e Bernard Andrieu (Universidade Paris Descartes), cujas pesquisas tocam ou inseremse na Filosofia do Corpo, revelam os trabalhos de jovens pesquisadores, tais como aqueles sobre 0 corpo e a estética da dança (PORPINO, 2006; MEDEIROS, 2010; VIEIRA 2012; VIANA, 2013), sobre o esporte (SILVA, 2014; MELO, 2014), bem como outros trabalhos de estudantes de graduação e mestrado ${ }^{1}$.

Como se percebe, esta apresentação sobre pesquisas, grupos de pesquisadores e obras não é, de modo algum, exaustiva. Trata-se apenas de um panorama, um olhar a partir de nosso conhecimento e intercâmbios com pesquisadores, a partir dos anos oitenta, mas também a partir das publicações disponíveis na internet. Nota-se, a partir destes cenários, uma expressiva rede de pensamento em torno da Filosofia do Corpo no Brasil, rede cujas articulações desenham-se também nos programas de pós-graduação, conforme veremos.

\section{A PRODUÇÃO ACADÊMICA EM FILOSOFIA DO CORPO}

A busca pelos dados da produção de conhecimento que trata da Filosofia do Corpo estruturou-se na análise das pesquisas desenvolvidas nos programas de pós-graduação stricto sensu recomendados pela Coordenação de Aperfeiçoamento de Pessoal de Nível Superior (CAPES).

Para obter informações destas pesquisas, realizamos visitas aos sítios eletrônicos desses programas e utilizamos o Banco de Teses da Capes para a coleta de informações sobre teses e dissertações, tendo como foco de análise os seus resumos. A escolha pelo banco de teses baseiase no fato de que muitos dos programas de pós-graduação não disponibilizam nos seus respectivos

\footnotetext{
${ }^{1}$ Esses intercâmbios começaram no ano de 2006, mas os primeiros frutos foram sistematizados através do I Simpósio Internacional Franco-Brasileiro "Corpo, Educação e Cultura do Movimento", realizado em outubro de 2014 na Universidade de Montpellier/França. Os trabalhos dos pesquisadores e de seus orientandos foram publicados em anais on line (http://www.sfb.univ-montp2.fr/wp-content/uploads/2015/01/Artigos-anais-Arquivo-\%C3\%BAnico.pdf) e na Revista Holos, do Instituto Federal de Educação, Ciência e Tecnologia do Rio Grande do Norte (IFRN) (http://www2.ifrn.edu.br/ojs/index.php/HOLOS/issue/view/65 ).
} 
endereços eletrônicos a produção acadêmica de seus cursos. Além disso, pode-se inferir que essa seja a base de dados mais completa, já que concentra trabalhos de todas as instituições brasileiras.

Inicialmente, fizemos uma busca geral, situada no período de 2010 a 2015, utilizando como palavras-chave filosofia do corpo, escolhida após diversas tentativas com palavras referentes ao contexto dos estudos de Filosofia do Corpo no Brasil, sendo esse termo o que apresentou uma maior ocorrência de resultados de pesquisas desenvolvidas no país.

Foi encontrado um total de 271 trabalhos com a presença do termo filosofia do corpo, em diversas áreas de conhecimento, no referido período. (Tabela 1).

Tabela 1. Produção acadêmica por área de conhecimento - 2010/2015

\begin{tabular}{|c|c|c|c|}
\hline $\begin{array}{r}\text { Área de } \\
\text { conhecimento } \\
\end{array}$ & Total & $\begin{array}{r}\text { Áreas de } \\
\text { conhecimento }\end{array}$ & Total \\
\hline Filosofia & 79 & Epistemologia & 2 \\
\hline Educação & 40 & História & 2 \\
\hline Artes & 25 & Linguística & 2 \\
\hline Psicologia & 24 & Literatura brasileira & 2 \\
\hline Letras & 16 & Música & 2 \\
\hline Fonoaudiologia & 11 & Saúde coletiva & 2 \\
\hline $\begin{array}{r}\text { Sociais e } \\
\text { humanidades }\end{array}$ & 7 & $\begin{array}{l}\text { Arquitetura e } \\
\text { urbanismo }\end{array}$ & 1 \\
\hline Teoria literária & 7 & Direito público & 1 \\
\hline Comunicação & 6 & $\begin{array}{l}\text { Doenças infecciosas } \\
\text { e parasitárias }\end{array}$ & 1 \\
\hline $\begin{array}{l}\text { Ensino de ciências } \\
\text { e matemática }\end{array}$ & 5 & Educação especial & 1 \\
\hline Sociologia & 5 & Educação física & 1 \\
\hline $\begin{array}{c}\text { Tratamento e } \\
\text { prevenção psicológica }\end{array}$ & 5 & $\begin{array}{l}\text { Enfermagem de } \\
\text { saúde pública }\end{array}$ & 1 \\
\hline Direito & 4 & $\begin{array}{l}\text { Engenharia/tecnolog } \\
\text { ia/gestão }\end{array}$ & 1 \\
\hline Enfermagem & 3 & $\begin{array}{l}\text { Literatura } \\
\text { comparada }\end{array}$ & 1 \\
\hline $\begin{array}{r}\text { Ensino- } \\
\text { aprendizagem }\end{array}$ & 3 & Psicologia cognitiva & 1 \\
\hline Teologia & 3 & Saúde e biológicas & 1 \\
\hline Antropologia & 2 & Saúde pública & 1 \\
\hline Dança & 2 & Teoria do direito & 1 \\
\hline Total de trabalhos & & 271 & \\
\hline
\end{tabular}

Após esse levantamento geral, e quantificados os dados, priorizamos para as nossas reflexões as teses e dissertações nas áreas da Educação e da Filosofia, mais especificamente nos 
NÓBREGA, SILVA \&LIMA NETO (2015)

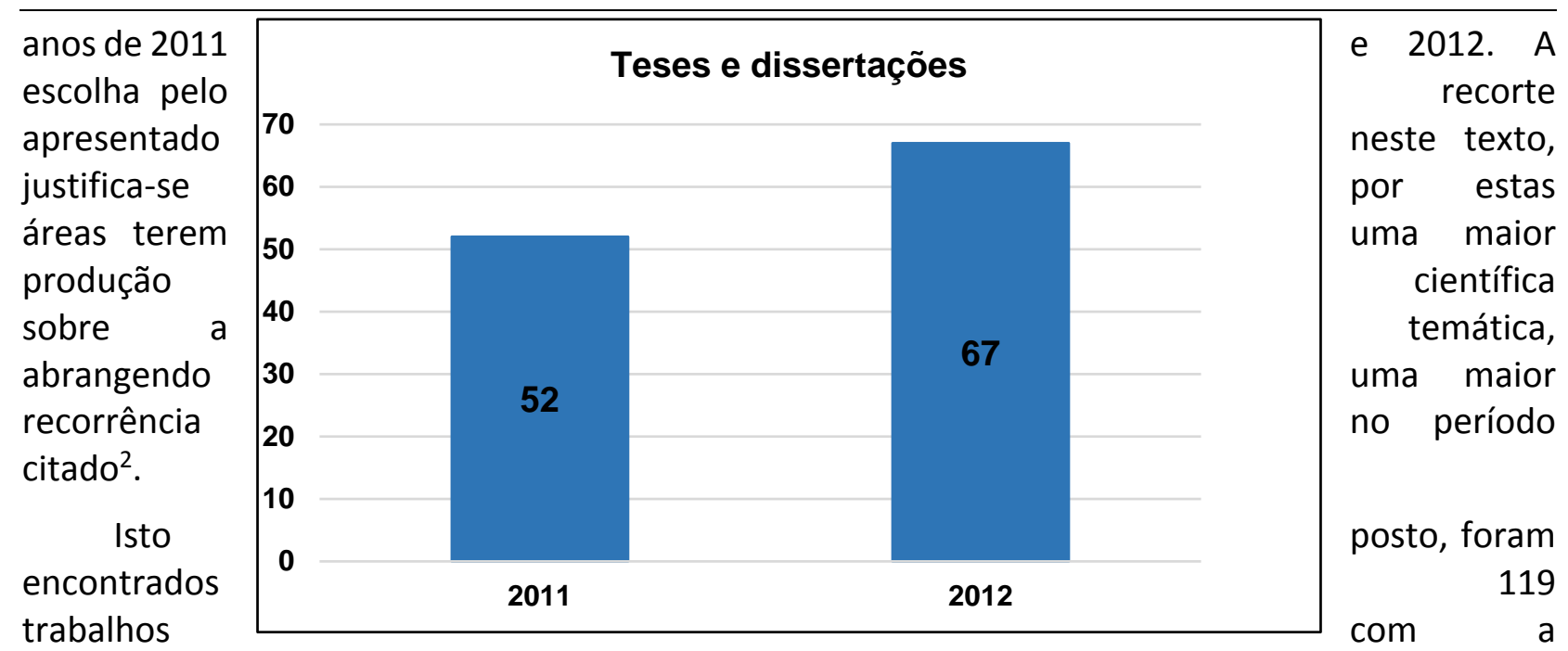

presença do termo filosofia do corpo, nas áreas da Educação e da Filosofia, no referido período, sendo 90 dissertações 29 teses (Tabela 2).

Tabela 2. Bando de Teses da Capes (2011 - 2014)

\begin{tabular}{c|c|c|c|c}
\hline Assunto & Dissertações & Teses \\
\hline Filosofia do corpo & 90 & 29 & 119 \\
\hline
\end{tabular}

Sobre os índices de produção científica, encontramos uma grande expansão da produção de teses e dissertações no período de 2011 e 2012 (Figura 1), o que pode estar vinculado ao aumento no número de programas de mestrado e doutorado em Educação e em Filosofia recomendados pela CAPES. Meneghel et al. (2007) aponta ainda a firmação de convênios entre universidades, no Brasil e no exterior, a contratação de docentes com títulos de doutores e mestres, acompanhado de infraestrutura física e de pessoal técnico-administrativo adequado, bem como o aumento no número de bolsas de pós-graduação, como fatores preponderantes para o aumento dos índices de produção científica de uma determinada área.

\footnotetext{
2 Encontramos nos anos de 2010 a 2014, quantitativa e respectivamente, 0, 52, 67, 0, 0. Com um total 79 trabalhos na área da Filosofia, e 40 trabalhos na área da Educação.
} 
Figura 1: Produção de teses e dissertações

A região Sudeste apresentou a maior concentração de produção acadêmica, seguida pela região Sul e pela região Nordeste, sendo as regiões Centro-oeste e Norte as que apresentaram menores índices de produção (Tabela 3).

Tabela 3. Dissertações e teses por Regiões - 2011/2012

\begin{tabular}{c|c|c|c}
\hline \multirow{2}{*}{ Regiões } & Dissertações & 0 & Total \\
\hline Norte & 1 & 8 & 1 \\
\hline Nordeste & 16 & 3 & 8 \\
\hline Centro-oeste & 5 & 13 & 52 \\
\hline Sudeste & 39 & 5 & 34 \\
\hline Sul & 29 & & \\
\hline
\end{tabular}

Meneghel et al. (2007), em um estudo sobre a produção do conhecimento científico no Brasil, afirma que desde meados dos anos de 1960, quando deu-se de forma mais sistematizada a institucionalização da pesquisa e da pós-graduação no país, as regiões Sul e Sudeste captaram a maior parte dos investimentos para produzir conhecimento, tecnologia e inovação a partir do desenvolvimento das chamadas pesquisas de ponta.

Como destacam os autores citados, apenas no final de 1980, sobretudo em 1990, houve nova expansão de Programas de Pós-graduação nas regiões fora do eixo geográfico e central de produção econômica do país e, tradicionalmente, com menor apoio de agências de pesquisa. Por extensão, com menor produção científica.

Do ponto de vista regional, Saviani (2002) destaca que o desequilíbrio nas produções científicas no Brasil apresenta-se em face das pesquisas permanecerem confinadas aos centros com maiores investimentos em bolsas e fomento à pesquisa. Ou seja: regiões com a maior concentração pessoal qualificado, recursos financeiros, infraestrutura física, doutores, ingressos de alunos e programas em nível de excelência (conceitos 5, 6 e 7) $)^{3}$.

\footnotetext{
${ }^{3}$ No Brasil, a Avaliação dos Programas de Pós-graduação envolve acompanhamento anual e avaliação trienal pela Coordenação de Aperfeiçoamento de Pessoal de Nível Superior/CAPES. Assim, os programas com conceitos 5, 6 e 7 possuem alto nível de desempenho, sendo os últimos, aqueles com desempenho equivalente aos de centros internacionais.
} 
Diante do exposto, apesar das Regiões Sul e Sudeste desenvolverem potente sistema de pósgraduação, em termos qualitativo e quantitativo, e ainda, apresentarem uma maior recorrência na produção científica, a região Nordeste dispõe de um número expressivo de publicações. O que anuncia uma ascensão e descentralização no campo da pesquisa no Brasil, cujo grande crescimento, nos últimos anos, resulta da criação de Programas de Pós-graduação para as chamadas regiões "periféricas", que tradicionalmente possuem carência de recursos financeiros e menor apoio de agências de pesquisa (SAVIANI, 2002).

A partir da análise das teses e dissertações, pode-se constatar um movimento nos estudos de Filosofia do Corpo no Brasil em diversas áreas de conhecimento, havendo uma maior incidência nas áreas da Educação e da Filosofia. Nestas, nos últimos 5 anos houve uma predominância de pesquisas no período de 2011 a 2012, destacando as regiões Sul e Sudeste como os principais centros de produção de conhecimento.

Com isso, se de um lado, há nesses anos uma recorrência significativa na produção científica referentes aos estudos de Filosofia do Corpo, de outro, ainda vemos as disparidades regionais dessas produções. O que evidencia a expressão mais potente nas regiões para onde é canalizado a maior parte dos investimentos realizados no desenvolvimento científico e tecnológico.

Os números expressos nos diferentes gráficos mostram-nos uma fotografia da produção. Os trabalhos analisados evidenciaram que na área da Filosofia e da Educação, o corpo cresce como objeto de investigação, sendo o principal elemento de incursão no ato de conhecer. Ao refletir sobre o conhecimento do corpo e o corpo como origem de conhecimento, sob diversas leituras conceituais, abordagens teóricas e epistemológicas, tais estudos nos oferecem senhas importantes para enfatizar e alargar, nos diversos campos de investigação, a presença da corporeidade como realidade ontológica e epistemológica.

\section{CENÁRIOS DE HOJE E PARA AMANHÃ}

Concordamos com Andrieu (2010) que o corpo se tornou um objeto para a filosofia, em especial a análise da percepção, da sensação e da emoção como temas que se atualizam para além da discussão em torno do dualismo corpo e alma presente desde a antiguidade greco-romana. A abordagem fenomenológica seguramente contribuiu para a desconstrução desse dualismo e ampliou as compreensões de corpo e movimento, sensibilidade e estética (NÓBREGA, 2010).

O contexto atual exige outros olhares sobre a corporeidade em sua polissemia, articulandose filosofia, ciências humanas e sociais, arte, psicanálise e educação. Há um vasto campo de questões e horizontes de investigação em torno do corpo e muitas agendas de pesquisa podem ser constituídas nesse movimento de pensamento. O corpo estesiológico e suas sensações configura um cenário contemporâneo para a pesquisa em filosofia do corpo, sobretudo ao articular-se com a perspectiva da emersiologia e os relatos em primeira pessoa do corpo vivo em experiências relacionadas ao esporte, a sexualidade, a arte, entre outros domínios da vida e do conhecimento (ANDRIEU, 2014; 2015). Nota-se ainda, como indica Imbert (2008), que uma educação do olhar enquanto tema de uma filosofia do corpo se faz necessária na contemporaneidade. Tal educação se articula com a arte, a pintura, a coreografia, o cinema.

Essas referências indicam a transição e a passagem de uma filosofia do corpo e suas relações com a consciências e com a linguagem para o investimento nas experiências do corpo, nas sensações do corpo em ato e na configuração de uma lógica sensível, apoiada não na 
representação da consciência ou da linguagem, mas na descontinuidade entre o corpo vivo e a experiência do corpo vivido, buscando-se novos regimes de inteligibilidade para a corporeidade e novas partilhas afetivas e sociais. Nesse sentido, os temas das sexualidades plurívocas, teoria queer, transgênero, corpos deficientes, artes imersivas, experiências autobiográficas da corporeidade, políticas do desejo, estesiologia e educação, ecologia corporal, são alguns dos cenários a serem investidos pela Filosofia do Corpo em suas interfaces com a Filosofia do Esporte e das práticas corporais, com a Educação Física e com os outros campos do saber aqui elencados.

A literatura indicada no corpo do nosso artigo desvela um panorama do movimento do pensamento em Educação Física, especificamente no tocante à Filosofia do Corpo. Apresentamos uma trajetória que se consolida ao longo das últimas décadas do século XX e cujas perspectivas são fecundas para a área - o que podemos observar nos indicadores das pesquisas desenvolvidas nos programas de pós-graduação stricto sensu recomendados pela Coordenação de Aperfeiçoamento de Pessoal de Nível Superior (CAPES). Esse panorama pode contribuir para uma maior visualização dessa temática e dessa abordagem de pesquisa como possibilidade de uma reflexão mais aprofundada sobre os modos de pensar, as diferentes lógicas e usos do corpo na cultura contemporânea, compreendendo-a também enquanto cultura do corpo.

\section{REFERÊNCIAS}

ANDRADE, Oswald. Manifesto antropófago. In: TELES, Gilberto Mendonça. Vanguarda europeia e modernismo brasileiro: apresentação e crítica dos principais manifestos vanguardistas. Petrópolis, RJ: Vozes, 2009.

ANDRIEU, Bernard. Donner le vertige : les arts immersifs. Montréal : Liber, 2014. Introduction. In: Philosophie du corps: Expériences, interactions et écologie corporelle. Paris: Vrin, 2010. Quelle épistémologie du corps ? Corps, 2006/1, n 1, p. 13-21. . La nouvelle philosophie du corps. Ramonville Saint-Agne: Éditions Érès, 2002. . Le corps dispersé: Une histoire du corps au XXe siècle. Paris: L'Harmattan, 1993. No corpo de minha mãe: método emersivo. Natal: Editora do IFRN, 2015 (no prelo).

2015. ; NOBREGA, T.P. Amérique du sud. In : (org.). Philosophie du sport. Paris : L'Harmattan,

ARAÚJO, A. C.; MELO, J. P. Entrelaçamento entre jogos olímpicos, educação e educação física escolar no Brasil. In: MOREIRA, W.; BENTO, J. (Orgs.). Citius, Altius, Fortius: Brasil, esportes e jogos olímpicos. Belo Horizonte: Casa da Educação Física, 2014.

BARREIRA, C. \& MASSIMI, M., 2008, O combate subtrativo: a espiritualidade do esvaziamento como norte da filosofia corporal no Karate-Do, Psicologia:Reflexão e Crítica, XXI, 2, 283-292.

BRACHT, V. Educacão Física e Aprendizagem Social. Porto Alegre: Magister, 1992.

; CRISÓRIO, R. (Orgs.). A Educação Física no Brasil e na Argentina: identidade, desafios e perspectivas. Campinas: Autores Associados, 2003.

CALMELS, D. Cuerpo y saber. Buenos Aires: D\&B, 1997.

. El libro de los pies: memoriales de un cuerpo fragmentado. Buenos Aires: Biblos, 2001.

CAMINHA, I. O. O distante-próximo e o próximo-distante: corpo e percepção na filosofia de Merleau-Ponty. João Pessoa: Editora Universitária da UFPB, 2010.

CAVALCANTI, K. B. Esporte para todos: um discurso ideológico. São Paulo: IBRASA, 1984.

CLARO, Edson. Método dança-educação física. São Paulo: Éditions d'Auteur, 1987.

COLETIVO DE AUTORES. Metodologia do ensino da educação física. São Paulo: Cortez, 1992.

DAÓLIO, J. Da cultura do corpo. Campinas: Papirus, 1995. 
DUARTE, N.; DELLA FONTE, S. Arte, conhecimento e paixão na formação humana: 7 ensaios de pedagogia histórico-crítica. Campinas: Autores Associados, 2010.

FERREIRA NETO, A. (Org.). Leituras da natureza científica do Colégio Brasileiro de Ciências do Esporte. Campinas: Autores Associados, 2005.

FRAGA, A. B. Exercício da informação: governo dos corpos no mercado da vida ativa. Campinas: Autores Associados, 2006.

IMBERT, Claude. Lévi-Strauss, le passage du nord-Ouest. Paris : L'Herne, 2008.

KUNZ, E. Educação Física, ensino e mudança. ljuí: Unijuí, 1991.

LE BOULCH, J. Rumo a uma ciência do movimento humano. Porto Alegre: Artes Médicas, 1987.

LIMA, H. Do corpo-máquina ao corpo-informação: o pós-humano como horizonte biotecnológico. Curitiba: Certa, 2010.

LIMA, Analwik T. P. Somos todos canibais: antropofagia, corpo e educação sensível. $197 \mathrm{f}$. Tese (Doutorado em Educação). Universidade Federal do Rio Grande do Norte: Natal, 2013. Disponível na Internet: http://www.ppged.ufrn.br/arquivos/teses_dissertacoes/teses\%20-\%202013/ANALWIK\%20TATIE

LLE\%2OPEREIRA\%20DE\%20LIMA\%20SOLCI.pdf . Acesso em 30 de março de 2015.

LIMA NETO, A. A. Prazer com Razão: Análise e Crítica da Ética Sexual Kantiana. Natal: Editora do IFRN, 2013. MARINHO, I. P. O conceito bio-sócio-filosófico da Educação Física em oposição ao conceito anátomofisiológico, Boletim de Educação Física, Rio de Janeiro, ano 4, n.10, p.7-29, 1944.

. Educação física, Recreação e jogos. São Paulo: Editora Brasil, 1971.

MEDEIROS, R. M. Uma educação tecida no corpo. São Paulo: Editora Annablume, 2010.

MEDINA, J.P.S. A educação física cuida do corpo... e "mente". Campinas: Papirus, 1987.

MENEGHEL, Stela M. et al. Produção de conhecimento no contexto brasileiro: perspectivas de instituições emergentes. Atos de Pesquisa em Educação: PPGE/ME FURB, Blumenau, v. 2, n. 3, p.444-460, 1 jan. 2007. Disponível em: <http://proxy.furb.br/ojs/index.php/atosdepesquisa/article/view/756>. Acesso em: 12 mar. 2015.

MOREIRA, W.W. Educação física: uma abordagem fenomenológica. Campinas: Editora da Unicamp, 1992. NÓBREGA, Terezinha Petrucia. Corpo, percepção e conhecimento em Merleau-Ponty, Estudos de Psicologia, 13, Natal, p. 141-148, 2008.

Corporeidade e educação física: do corpo objeto ao corpo sujeito. Natal: Editora da UFRN, 2000.

. Uma Fenomenologia do Corpo. São Paulo: Editora Livraria da Física, 2010.

Ortega F. Le corps incertain : corporalité, technologies médicales et culture contemporaine. Brasil : Garamond, 2008.

PORPINO, K. Dança é educação: interfaces entre corporeidade e estética. Natal: Editora da UFRN. 2006.

SANTIN, S. Educação Física, uma abordagem filosófica da corporeidade. ljuí/RS: Editora Unijuí, 1987.

SARAVI REVIERE J. Aportes para una historia de la Educación Física 1900 a 1945. Editorial IEF № 1 "Dr. Enrique Romero Brest" Bs. As. Argentina, 1998

SAVIANI, D. A pós-graduação em educação no Brasil: pensando o problema da orientação. In: BIANCHETTI, Lucídio et al (orgs). A Bússola do Escrever: desafios e estratégias na orientação de teses e dissertações. Florianópolis: Ed. da UFSC, 2002, p.135-163.

SCHEINES G. I. Juguetes y jugadores. Buenos Aires: Belgrano, 1981.

. Los Juegos de la vida cotidiana. Eudeba: Buenos Aires, 1985.

SÉRGIO, M. Educação Física ou ciência da motricidade humana. Campinas: Papirus, 1989.

SILVA, A. M. Corpo, ciência e mercado: reflexões acerca da gestação de um novo arquétipo da felicidade. Campinas/Florianópolis: Autores Associados/Editora da UFSC, 2001.

SILVA, L. M. F.; PORPINO, K. O.; Torres, L. S., Corpo e Técnica em Olympia, Recorde: Revista de História do Esporte, v. 7, p. 1-11, 2014.

SILVEIRA, V. T.; Vaz, A. F. Doping e controle de feminilidade no esporte, Cadernos Pagu (UNICAMP. Impresso), v. 42, p. 447-475, 2014.

SOARES, C. L. Educação Física: raízes europeias e Brasil. Campinas: Autores Associados, 1994.

SOARES, C. L. Imagens da educação no corpo. Campinas: Autores Associados, 1998. 
STOKOE, P.; HARF, R. Expressão corporal na pré-escola. São Paulo: Summus, 1987.

SOUSA FILHO, Alípio. Brésil: terre de métissages. Imaginaire et quotidien dans la société brésilienne. Saarbrücken: Éditions Universitaires Européennes, 2011.

TEIXEIRA, M. S. Fundamentos filosóficos da Educação Física (Philosophical Foundations of Physical Education). São Paulo: Obelisco, 1970.

TORRES, C. R.; CAMPOS, D. G. La pelota no dobla? Ensayos filosóficos en torno al fútbol. Buenos Aires: Libros del Zorzal, 2006.

; Niñez, deporte y actividad física: reflexiones filosóficas sobre una relación compleja. Buenos Aires: Miño y Dávila Editores, 2008.

VAREA, Valeria; GALAK, Eduardo (Orgs.). Cuerpo y Educación Física: perspectivas latinoamericanas para pensar la educación de los cuerpos. Buenos Aires: Biblos, 2013.

VELOSO, Caetano. Língua. In: Homem comum. 2003.

VIANA, R. N. A. O bumba meu boi como fenômeno estético. São Luís: EDUMA, 2013.

VIEIRA, M. S. Pastoril: uma educação celebrada no corpo e no riso. Jundiaí: Paco Editorial, 2012. 